\title{
A new portable vibrator for plaster pouring: effect on the marginal fit at cylinder-abutment
}

\author{
Pâmela Cândida Aires Ribas de ANDRADE'1, Leonardo Flores LUTHI², Kyle STANLEY³, Antônio Carlos CARDOSO ${ }^{4}$
}

\author{
1- DDS, MSc, PhD student, Department of Implant Dentistry, Federal University of Santa Catarina, Florianópolis, SC, Brazil. \\ 2- DDS, MSc, PhD student, Department of Dental Materials and Prosthodontics, University of Campinas, Piracicaba School of Dentistry, Piracicaba, SP, Brazil. \\ 3- MSc student, Department of Implant Dentistry, Federal University of Santa Catarina, Florianópolis, SC, Brazil. \\ 4- DDS, MSc, PhD, Full Professor, Department of Implant Dentistry, Federal University of Santa Catarina, Florianópolis, SC, Brazil.
}

Corresponding address: Pâmela Cândida Aires Ribas de Andrade - Universidade Federal de Santa Catarina/CCS/DEPTO STM - Campus Universitário, s/n - 88040-970 - Trindade - Florianópolis - SC - Phone: + 55 (48) 37219077 / + 55 (48) 91645150 - Fax: (48) 3721-9077 - e-mail: pam_ribas@yahoo.com.br

Received: May 26, 2011 - Modification: August 04, 2011 - Accepted: September 05, 2011

\section{ABSTRACT}

\begin{abstract}
bjective: The aim of this study was to test a new portable vibrator for plaster pouring (developed for this purpose), comparing the effect of its use on the accuracy of working cast of implant-supported restorations to the conventional vibrator. Material and methods: From a master cast with 2 implants, 30 transfer moldings were made randomly and divided into three groups: Group I (GI): pouring performed in an outsourced dental laboratory with conventional plaster vibrator (10 casts), Group II (GII): pouring performed in the laboratory of the Federal University of Santa Catarina (UFSC) with conventional plaster vibrator (10 casts) and Group III (GIII): pouring performed with the portable vibrator fabricated for this study (10 casts). The position of the analogue and marginal adaptation of the infrastructure were verified by testing the single screw on the master model and on the working model. The measurement of misfit was blindly performed with a precision microscope and analyzing unit, Quadra-Check 200. The data were statistically analyzed by analysis of variance (ANOVA) and the Holm-Sidak test $(\alpha=0.05)$. Results: Means \pm standard deviations were as follows: GI: 19.19 $\pm 4.73 \mu \mathrm{m}$; GII: $21.72 \pm 5.41 \mu \mathrm{m}$; GIII: $13.5 \pm 2.39$ $\mu \mathrm{m}(\mathrm{P}<0.05)$, with GIII significantly lower as compared to the other groups. Conclusion: Within the limitations of this study, it was concluded that a greater accuracy of working cast was achieved when a portable vibrator was used for casting molds.
\end{abstract}

Key words: Plaster casts. Implant-supported dental prosthesis. Dental impression materials.

\section{INTRODUCTION}

The oral rehabilitation of patients with implants requires the placement of stable prostheses enabling security, comfort and longevity to treatment. The beginning of the construction of prosthetic treatment requires the faithful reproduction of the working cast of the situation found in mouth, to reduce the errors inherent to this stage ${ }^{17}$.

Numerous studies ${ }^{2,8,9,19}$ have tried to find the "perfect" fit between prosthetic components and the implant. However, the variables found in the steps of the clinical and laboratory procedures involved in the fabrication prostheses become an obstacle in the search for a perfect fit ${ }^{7}$, leading to errors that make it impossible to obtain a dental implant with a perfect framework fit ${ }^{12}$.

During the production stages of a cast, some processes may influence the correct analogue position of the working cast, increasing the chances of distortion and misfit of the final prosthesis ${ }^{6}$. The casting material used ${ }^{2}$, the casting technique ${ }^{2,7,11}$ and the casting impression conditions are factors that can influence the accurate reproduction of the clinical situation ${ }^{18}$.

Another important aspect to be considered is the step of sending the molds to the laboratory. A study by Christensen ${ }^{5}$ (1997) demonstrated that most jobs ready to be poured with gypsum were deficient in some aspect ${ }^{6}$. The literature ${ }^{2,7,11}$, although large and concerned with the techniques and impression materials, is scarce when dealing with the variables of everyday practice. A small number of studies 
focused on the influence of factors such as casting of the plaster cast ${ }^{14}$ or the technique for casting on dimensional changes of the casts.

In an attempt to minimize distortions in the procedures for obtaining a working cast, improve the accuracy of implant prostheses and assist dentists, we developed a small, silent and portable vibrator. We hypothesized that this device would be able to reduce the vibration generated by conventional devices, thus leading to fewer changes in the working cast, better adaptation between the cylinders of implant-supported dentures and their respective analogues. This would result in a more faithful copy of the situation in the mouth, with minimal bubbles and dimensional change in the working cast.

The purposes of this study were to test the technique of casting plaster using this portable vibrator device, comparing it with conventional methods, and to evaluate the influence of this device on the position of implant analogue working casts.

\section{MATERIAL AND METHODS}

A master acrylic resin template (Palaton Dencril, Pirassununga, SP, Brazil) of a Class IV edentulous maxillary arch, with two external hexagonal implants $\varnothing 3.75 \times 11 \mathrm{~mm}$ (Master Screw; Conexão Sistemas de Próteses, São Paulo, SP, Brazil) positioned in the region of the maxillary right lateral incisor $(A)$ and maxillary left lateral incisor (B) was manufactured for the study design (Figure 1). Two abutments (Micro-unit; Conexão Sistemas de Próteses, Arujá, SP, Brazil) were installed by manual ratchet key until a torque of $20 \mathrm{~N} . \mathrm{cm}$ was produced according to the manufacturer's directions and 30 transfer moldings were made with open trays. This cast was then randomly divided into three groups, depending on the plaster casting technique:

Group I (GI): pouring performed at an outsourced dental laboratory with conventional plaster vibrator (10 casts);

Group II (GII): pouring performed at UFSC laboratory with conventional plaster vibrator (10 casts);

Group III (GIII): pouring performed with the portable vibrator fabricated for this study (10 casts).

To make the impressions, standard size (no. 3) perforated plastic trays were used (JG, JON, São Paulo, SP, Brazil), with an opening at the top of two holes designed for the removal of screws for transferring squares. The material of choice for the impression was polyvinyl siloxane (PVS) (Express XT Silicone Addition, 3M ESPE, USA) ${ }^{19}$ and manipulation was done by the single step double impression technique ${ }^{7,11}$. The transfer copings were screwed in their abutments in the master cast and splinted together with a metal rod and acrylic pattern resin (Trim Plus Red - Acrylic Pattern; Harry J. Bosworth Company, Skokie, IL, USA $)^{9}$, reducing the distortion of polymerization. After 10 min of union with transferring acrylic resin, heavy-body PVS was handled according to the manufacturer's instructions and the tray was loaded with the material, while light-body PVS was injected into the region of the implants and their components. To standardize the molding, heavybody PVS was measured in a plastic syringe injector for elastomer (JON) filled with slurry by cast. Setting of the dummy tray was held constant with manual pressure until it clicked into a reference point located on the mannequin, then held in position for $10 \mathrm{~min}$ to complete polymerization of the material. All impressions were made in the same temperaturecontrolled air conditioning between $18^{\circ} \mathrm{C}$ and $22^{\circ} \mathrm{C}$. After the mold was ready, the transfer copings were loosened to remove the impression and screwed to the respective analogues of the abutments (Conexão Sistemas de Próteses). For all transfer copings a torque of $10 \mathrm{~N} . \mathrm{cm}$ was applied manually with a keyed ratchet (Conexão Sistemas de Próteses), but the placement of analogues was performed with a digital grip, because the torque applied by a $10 \mathrm{~N} . \mathrm{cm}$ ratchet could cause rotation of the transferor PVS ${ }^{2,8}$. Adaptation of impressions prior to the tightening grip and digital analogue was again verified by the transferor with explorer no. 05 (Duflex SS White, Rio de Janeiro, RJ, Brazil).

When the impressions were ready, with the union of the analogues, they were randomly assigned to groups according to the technique of casting plaster. The 30 plaster casts used microgranulated special type IV plaster (Durone, Dentisply, Petrópolis, RJ, Brazil), and pouring was conducted in an area for at least 60 min and at most 3 days after the order was ready.

\section{Fabricating the portable vibrator}

For casting plaster of Group III, we developed a portable vibrator made from an electric toothbrush (360 Sonic Power, Colgate Palmolive Ind. e Com. São Paulo, SP, Brazil). The bristles of the brush were removed using a carborundum disk-type cutter and maxi-cut, and a hole in the place of the bristles was made for installation of the tip of a brush on the opposite side (round marta brush Tropical 006, Tigre, São Paulo, SP, Brazil), maintaining a slight inclination toward the end to facilitate placement of the plaster inside the impression (Figure 1).

\section{Casting molds for Group I}

Ten impressions were sent to the outsourced laboratory, in a routine procedure for work on 
prosthetic implants. Along with the impressions, an order tab was included with the request for plaster casting of special type IV, for a minimum standardization with the other groups.

\section{Casting molds for Groups II and III}

The casts of Groups II and III were poured with $100 \mathrm{~g}$ of powder type IV gypsum, proportioned to $22 \mathrm{~mL}$ of water ${ }^{6,8}$ and hand-mixed for $60 \mathrm{~s}$. Insertion of the plaster cast was performed according to the technique assigned to each group, with Group II using the leaked vibrator with conventional casting and Group III with the portable vibrator. After a period of at least $1 \mathrm{~h}$ of setting time for the plaster, the working casts were removed from the mold. All casts were stored at room temperature for at least $92 \mathrm{~h}$ before assessment of misfit ${ }^{8}$. To standardize the samples, all steps of molding, tooling, and casting of plaster were made by the researcher in charge, while handling the PVS was done by an assistant operator.

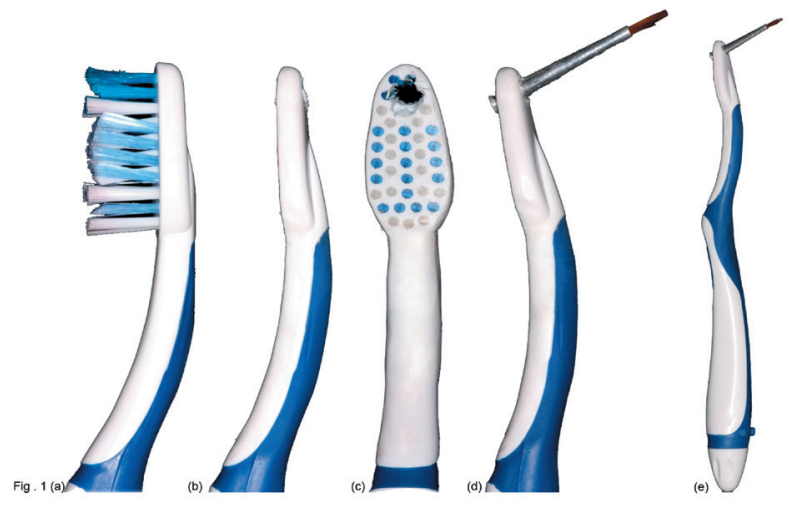

Figure 1- Step-by-step fabrication of the portable device designed to casting plaster (a): electric toothbrush; (b): bristles of the brush removed; (c): hole on tip of the toothbrush in place of the bristles; (d): installation of the tip of a brush on the opposite side of the bristles and (e): portable vibrator ready
Evaluation of discrepancies in the position of casts and analogues

Verification of the accuracy of the position of analogues and comparison between groups was performed to develop an infrastructure (IE) from two metal cylinders of titanium abutment microunit, bolted to the abutment of the master cast (MC) and joined together by a titanium bar and laser welding ${ }^{10}$.

To calculate the misfit of the casts and make comparisons between groups, we measured the vertical misfit of IE in the MC to verify the reliability of the adaptation and the value of the initial IE misfit ${ }^{20}$. Then, the evaluations also were carried out in testing casts (TC) of Groups I, II, and III, with IE placed on them, whose respective averages were subtracted from the initial value obtained for MC in order to obtain the real misfit value. The implants of $\mathrm{MC}$ and related analogues of the tested casts were recorded as $A$ and $B$, from left to right, as with the cylinders of IE. Evaluation of misfit was based on the protocol of tightening the screw only to test the passivity of the implant structures ${ }^{15}$, which had the grip of a retainer and evaluation of the contrary retainer ${ }^{15}$ (Figure 2 ).

The misfit was measured at $120 x$ magnification in a measuring microscope accurate to $1.0 \mu \mathrm{m}$ (UHL MM-100-BT, UK), equipped with a digital camera (KC-512NT; Kodo BR Electronics Ltd., São Paulo, SP, Brazil) and analyzer unit (QC 220-HH QuadraCheck 200; Metronics Inc., Bedford, NH, USA). The casts were placed randomly under the microscope so that the blind evaluator did not know to which group they belonged. All casts were evaluated at identical points and cylinders $A$ and $B$ of IE were marked with a carborundum disk $\varnothing 75 \times 0.2 \mathrm{~mm}$ on the handpiece.

The readings were performed by an examiner on two calibrated points on the buccal ( 1 and 2 ) and two in the lingual face ( 3 and 4 ), ordered from left to right. The sequence of assessment was followed by the tightening of the screw in the implant B with 10 N.cm and measuring the distance in micrometers

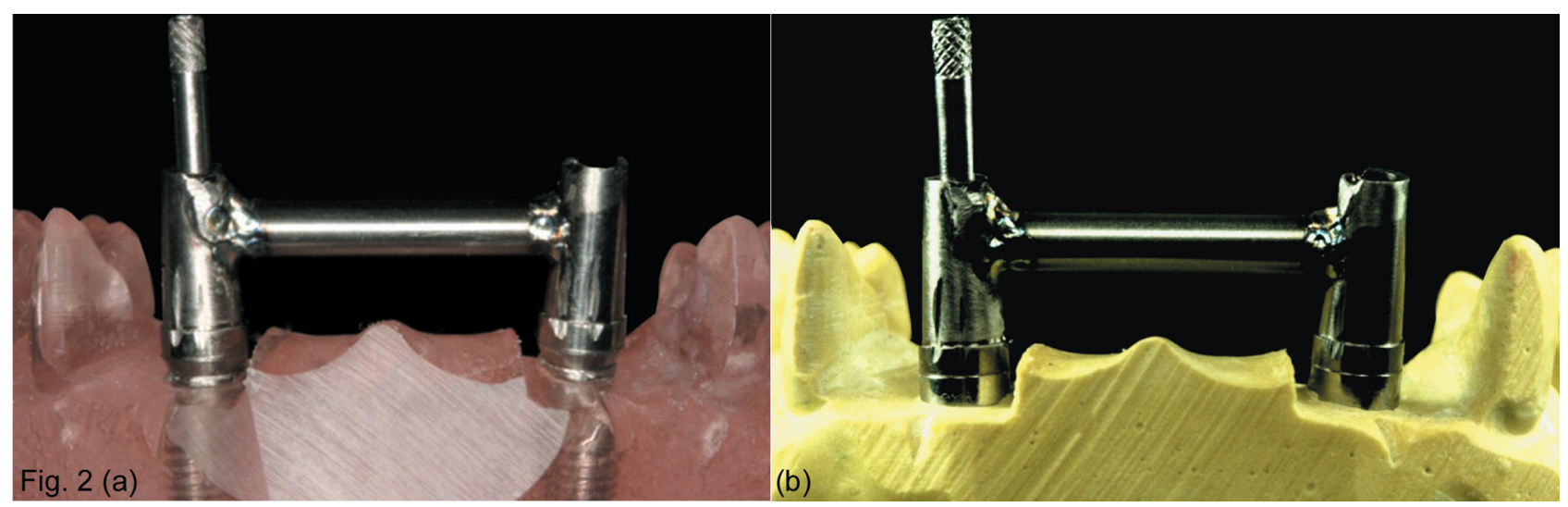

Figure 2- Infrastructure placed on the master cast (MC) (a) and the test cast (TC) (b) to test the single screw 
$(\mu \mathrm{m})$ of 1-4 points on the interface of the cylinder to the abutment/analogue interface, identifying the considered misfit (Figure 3). The same procedure was then performed for $\mathrm{B}$. Each point was measured three times and the average value used for the analysis.

\section{Statistical analysis}

Means and standard deviations for each plaster casting technique were calculated and analyzed by one-way ANOVA to determine whether there were significant differences between groups, at $a=0.05$. After ANOVA, data were subjected to Holm-Sidak multiple comparison test, which identified the $p$ values. The software used was Sigmastat 3.5 (Systat Software, Inc., Chicago, IL, USA).

\section{RESULTS}

Data analysis revealed a statistically significant difference between Group III as compared to Groups I and II $(p<0.001)$ (Figure 4). This means that the technique of casting the plaster with a

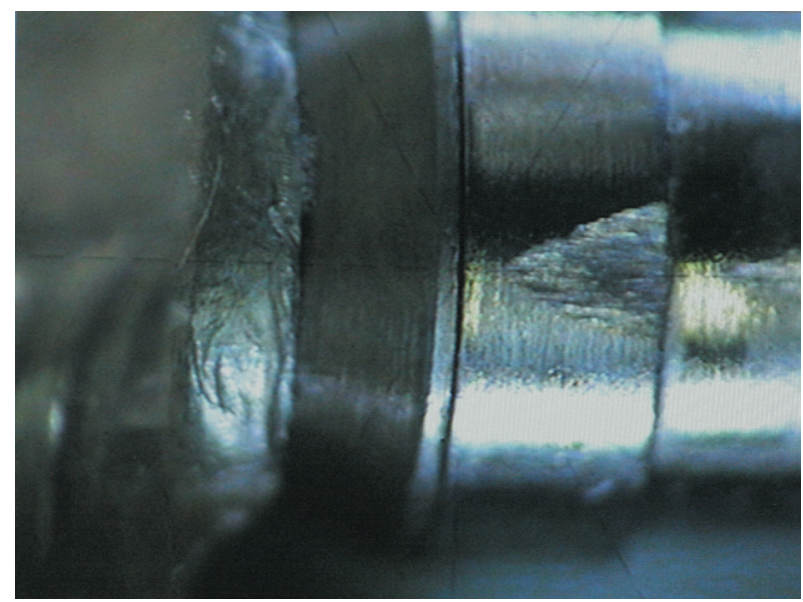

Figure 3- Microscopic image of the misfit generated at the interface of one point portable vibrator produces a smaller misfit between cylinders of implant-supported dentures and their respective analogues in comparison with the conventional techniques for casting plaster.

\section{DISCUSSION}

For the construction of a fixed partial denture on implants, several steps must be followed to reduce errors and obtain a clinically acceptable product. According to dental knowledge, the larger the number of pontics and retainers in prosthesis, the greater the chances of mismatch. Since the installation of the abutment to the working model, there are countless chances of errors ${ }^{2,5-7,11,18}$. Also, the fact that the analogues are screwed to the implant makes them susceptible to displacement, especially during vibration of plaster during pouring.

This work aimed to check the effectiveness of a new portable vibrator on the plaster pouring of implant-supported dentures, also to verify if this device reduces the possibility of misfit between cylinders of implant-supported dentures and their respective analogues. The results of the present work showed that the portable vibrator led to lower misfit values between cylinders of implant-supported dentures and their respective analogues when compared to conventional vibrator. A minimum misfit was found when using the new vibrator, but the "perfect" adaptation is almost impossible to reach ${ }^{20}$.

Extrapolating to clinical results of acceptable misfit of an implant-supported prosthesis, the literature ${ }^{3,16}$ is unable to show an ideal value of adjustment that will not jeopardize the entire system for prosthetic reconstruction. According to Tossi ${ }^{16}$ (2010) values of marginal fit between frameworks to multiple-units are clinically acceptable within $150 \mu \mathrm{m}$ range ${ }^{16}$. Carr ${ }^{3}$ (1996) in an in vivo study on primates verified that there is no statistically significant difference in bone response around the

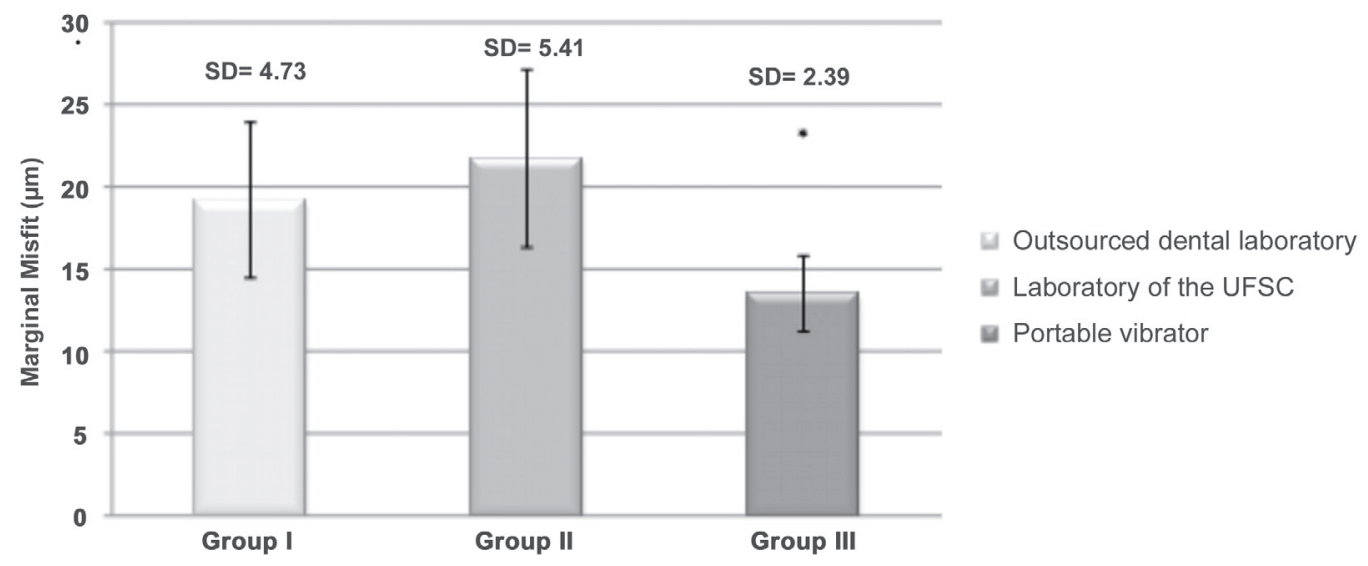

Figure 4- Means and standard deviations(SD) of the misfit $(\mu \mathrm{m})$ for the three groups.

${ }^{*}$ statistically significant difference in comparison with the other groups $(p<0.05)$ 
implants supporting frameworks with $38 \mu \mathrm{m}$ and $345 \mu \mathrm{m}$ misfits $^{3}$.

According to literature ${ }^{1,4,12}$ the marginal misfit can be influenced by the technique ${ }^{1}$ and by the material ${ }^{4,12}$ used to fabricate the frameworks. However, this research suggests that the vibration is also an important factor at this point, reminding that it refers to just one of many steps that are required to get a prosthetic piece. During the other steps required to complete prosthesis fabrication, such as firing porcelain several times and finishing ${ }^{13}$ done by a laboratory technician, misfit values will be further enhanced, thus emphasizing the importance of using laboratory techniques and devices that decrease the possibility of distortion in the final piece.

The new portable vibrator not only contributes to decrease the misfit, but also has the advantage of being a small, soundless and low-cost device.

\section{CONCLUSION}

The casting technique using the portable vibrator allowed a smaller misfit between the cylinders of implant-supported dentures and their respective analogues than the conventional plaster vibrator.

\section{ACKNOWLEDGMENTS}

The author would like to thank Dr. Guilherme Elias Pessanha Henriques and Dr. Mauru Antônio Arruda Nóbilo, Professors of Dentistry at the University of Campinas, SP, Brazil for his contribution and support to this work.

\section{REFERENCES}

1- Barbosa GA, Neves FD, Mattos MG, Rodrigues RC, Ribeiro RF. Implant/abutment vertical misfit of one-piece cast frameworks made with different materials. Braz Dent J. 2010;21:515-9.

2- Barret MG, Rijk WG, Burgess JO. The accuracy of six impression techniques for osseointegrated implants. J Prosthodont. $1993 ; 2: 275-82$

3- Carr AB, Gerard DA, Larsen PE. The response of bone in primates around unloaded dental implants supporting prostheses with different levels of fit. J Prosthet Dent. 1996;76:500-9.

4- Castilio D, Pedreira AP, Rossetti PH, Rossetti LM, Bonachela WC. The influence of screw type, alloy and cylinder position on the marginal fit of implant frameworks before and after laser welding.
J Appl Oral Sci. 2006;14:77-81.

5- Christensen JG. What category of impression material is best for your practice? J Am Dent Assoc. 1997;128:1026-8.

6- Del'Acqua MA, Arioli-Filho JN, Campagnoni MA, Mollo FA Jr. Accuracy of impression and pouring techniques for an implantsupported prosthesis. Int J Oral Maxillofac Implants. 2008;23:22636.

7- Hsu CC, Millstein PL, Stein RS. A comparative analysis of the accuracy of implant transfer techniques. J Prosthet Dent. 1993;69:588-93.

8- Inturregui JA, Aquilino SA, Ryther JS, Lund PS. Evaluation of three techniques for osseointegrated oral implants. J Prosthet Dent. 1993;69:503-9.

9- Jemt T. In vivo measurements of precision of fit involving implant-supported prostheses in the edentulous jaw. Int J Oral Maxillofac Implants. 1996;11:151-8.

10- Jemt T, Lindén B. Fixed implant-supported prostheses with welded titanium frameworks. Int J Periodontics Restorative Dent. 1992;12:177-84.

11- Luthardt RG, Walter MH, Weber A, Koch R, Rudolph H. Clinical parameters influencing the accuracy of 1- and 2-stage impressions: a randomized controlled trial. Int ] Prosthodont. 2008;21:322-7.

12- Moraes LM, Rossetti PH, Rossetti LM, Pedreira AP, Valle AL, Bonachela WC. Marginal fit at cylinder-abutment interface before and after overcasting procedure. J Appl Oral Sci. 2005;13:366-71. 13- Naveen HC, Pillai LK, Porwal A, Nadiger RK, Guttal SS. Effect of porcelain-firing cycles and surface finishing on the marginal discrepancy of titanium copings. J Prosthodont. 2011;20:101-5. 14- Podshadley AG, Dilts WE, Neiman R, Sawyer HF. Accuracy of a mercaptan rubber impression technique using a stock tray. J Am Dent Assoc. 1971;83:1303-8.

15- Sartori IA, Ribeiro RF, Franscischone CE, Mattos MG. In vitro comparative analysis of the fit of gold alloy or commercially pure titanium implant-supported prostheses before and after electroerosion. J Prosthet Dent. 2004;92:132-8.

16- Tossi R, Falcão-Filho H, Aguiar Júnior FA, Rodrigues RC, Mattos MG, Ribeiro RF. Modified section method for laser-welding of ill-fitting cp $\mathrm{Ti}$ and $\mathrm{Ni}-\mathrm{Cr}$ alloy one-piece cast implant-supported frameworks. J Oral Rehabil. 2010;37:359-63.

17- Waskewicz GA, Ostrowski JS, Parks VJ. Photoelastic analysis of stress distribution transmitted from a fixed prosthesis attached to osseointegrated implants. Int J Oral Maxillofac Implants. 1994;9:405-11.

18- Wee AG. Comparison of impression materials for direct multiimplant impressions. J Prosthet Dent. 2000;83:323-31.

19- Wenz HJ, Hertrampf K. Accuracy of impressions and casts using different implant impression techniques in a multi-implant system with an internal hex connection. Int J Oral Maxillofac Implants. 2008;23:39-47

20- Yanase RT, Binon PP, Jemt T, Gulbransen HJ, Parel S. How do you test a cast framework fit for a full-arch fixed implant-supported prosthesis? Int J Oral Maxillofac Implants. 1994;9:469-74. 